\title{
Comparison of Blade Dimension Design of a Vertical Wind Turbine Applied in Low Wind Speed
}

\author{
Rizky Brillian Yuliandi ${ }^{1, *}$, Rusdianasari ${ }^{2}$, and Tresna Dewi ${ }^{3}$ \\ 1Applied Master of Renewable Energy Politeknik Negeri Sriwijaya, 30139 Palembang, Indonesia \\ ${ }^{2}$ Chemical Engineering Department State Politeknik Negeri Sriwijaya, 30139 Palembang, Indonesia \\ ${ }^{3}$ Electrical Engineering Department State Politeknik Negeri Sriwijaya, 30139 Palembang, Indonesia
}

\begin{abstract}
The type of vertical turbine used for this research was a savonious where the profile of the blade was made in the form of a half-cylinder. The performance of the turbine rotation was strongly influenced by the swept area. Drag and lift force was influenced by the swept area. Both of the forces had its own advantages and disadvantages. Because of that, the dimensional engineering was implemented to obtain the optimal performance of the turbine. Experimental dimensions were tested with the variation of height size $(\mathrm{H}=40 \mathrm{~cm}$ and $60 \mathrm{~cm})$ and diameter size $(\mathrm{D}=40 \mathrm{~cm}$ and $60 \mathrm{~cm})$. The distance between the blades known as the overlap ratio was related to the dimensions. Overlap ratio has a role to the upwind and downwind wind flow because the overlap ratio changes affect the swept area. The experimental variation of the overlap ratio was at the distance of 0 $\mathrm{cm}$ and $10 \mathrm{~cm}$. The experimental results concluded that the best turbine performance was obtained during wind turbine testing with $\mathrm{H}$ $=40 \mathrm{~cm}$ and $\mathrm{D}=60 \mathrm{~cm}$ on primary overlap value minus $10 \mathrm{~cm}$ and secondary overlap $0 \mathrm{~cm}$.
\end{abstract}

\section{Introduction}

Renewable energy is one of the answer to the depletion of non renewable energy availability and the solution to reduce environmental damage caused by the use of fossil energy [12]. Wind energy is one of the renewable energy [2]. The quality and quantity of wind in most of areas are low-speed characteristics where the engineering of wind energy is necessary because of its large and efficient potential in the future [10]. The medium used for wind energy is a wind turbine. According to the axis of its blade rotation, wind turbine is classified into two types which are horizontal axis dan vertical axis [4]. When comparing between horizontal axis wind turbine (HAWT) and vertical axis wind turbine (VAWT) to

* Corresponding author: rizki.s2terapan@polsri.ac.id 
the potential of wind energy utilization with low-speed characteristics, VAWT is more qualified to be the preferred medium of wind energy utilization $[1,3,5]$.

VAWT is a turbine with an axis of the blades perpendicular to the wind direction [13]. Because of it, VAWT does not require a configuration for the blade direction in extracting wind energy. Basically, there are two types of VAWT which are savonius and darieus, as for some other types are the development of both types [6]. The purpose of this vertical wind turbine study is to improve the efficiency of vertical turbines, where savonius turbines have lower efficiency values than Darieus [11]. Low savonius efficiency is due to turbine working principle only utilizing more drag force dominantly and not even utilizing lift force as an effort to improve the performance of turbine rotation like darrieus turbine $[8,9]$.

Research was conducted by making and testing the comparison of savonius dimensions, where the variable of turbine dimension savonius have a crucial role to turbine rotation performance because wind energy can be converted by turbine depend on its swept area. Swept area (As) is an effective quantity of blade turbine that receives kinetic energy from wind and converts it into mechanic energy $[14,15]$. The variable of wind turbine swept area is the dimension of turbine consist of diameter and height of turbine and also the value of overlap ratio [7]. Overlap ratio is the ratio of the distance between the blades to the wind turbine, the distance between the blades in the vertical turbine known as the primary overlap (a) and the secondary overlap (e) [3]. Primary overlap has two distinct characteristics. If the distance between the interceptibles are close to each other, it is called the minus primary overlap. Otherwise, it is called the plus primary overlap. Overlap ratio is very influential on turbine performance [4].

\section{Materials and Methods}

The study began with the literature study of the theory development and the study of savonious turbine experiments. The results of the literature study were the basis to determine the flow of manufacturing and testing of savonious turbine.

Turbine visualization is shown in Figure 1. Description of Figure 1a is the installed turbine, Figure $1 \mathrm{~b}$ is a height ratio, Figure $1 \mathrm{c}$ is the ratio of diameter. Savonius turbine was designed by having three variations of blade dimension where turbine $1(\mathrm{D}=40 \mathrm{~cm}, \mathrm{H}=$ $40 \mathrm{~cm})$, turbine $2(\mathrm{D}=40 \mathrm{~cm}, \mathrm{H}=60 \mathrm{~cm})$, and Turbine $3(\mathrm{D}=60 \mathrm{~cm}, \mathrm{H}=40 \mathrm{~cm})$.

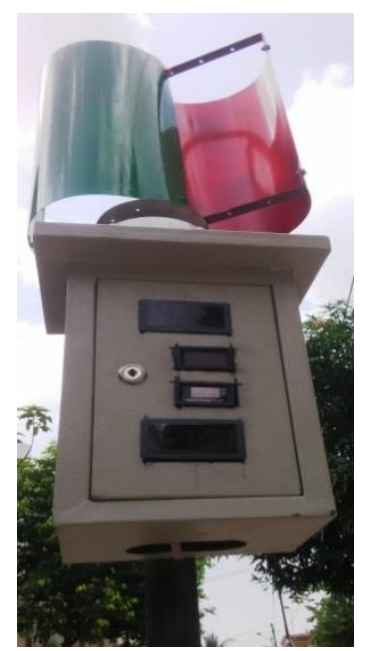

Fig 1a. VAWT

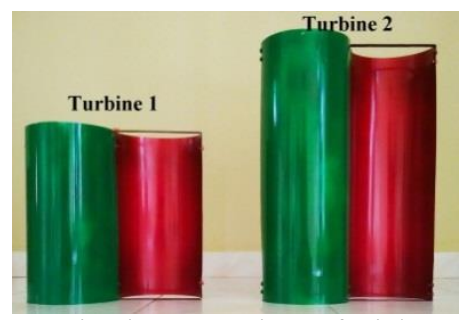

Fig 1b. Comparison of High

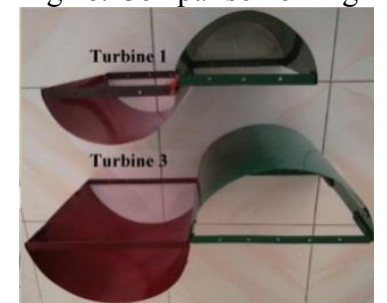

Fig 1c. Comparison of Diameter 
Fig. 1. Turbine Visualization

Specification of savonious turbine design and fabrication used aluminum material with $1.3 \mathrm{~mm}$ thickness and as a tool of converting turbine rotation into electrical energy using a dc generator with maximum output 100 watt and 24 volt.

Illustration of vertical wind turbine testing is shown in Figure 2. Wind speed was simulated using blower with the condition of the wind speed variation started from $0 \mathrm{~m} / \mathrm{s}$ until $5 \mathrm{~m} / \mathrm{s}$.

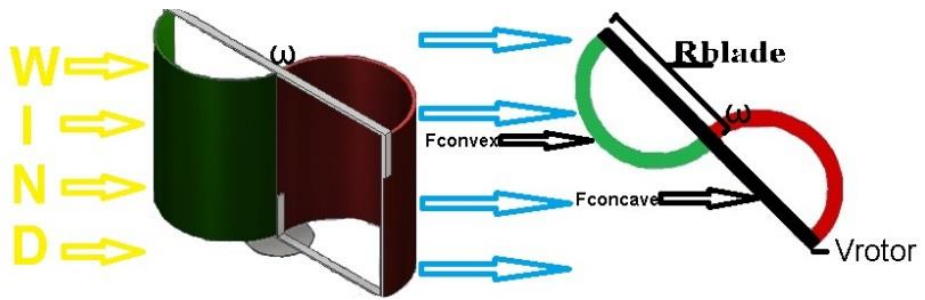

Fig. 2.Illustration of wind turbine testing process

Observations were carried out by analyzing the effect of wind speed on the turbine rotation and the electrical energy generated without the load connected to the output of wind turbine. In addition to the dimension variations based on the difference in height and diameter under normal conditions (the overlap ratio at a distance of $0 \mathrm{~cm}$ ), the test was also done by changing the overlap ratio in the minus and plus overlap minus at a distance of 10 $\mathrm{cm}$, and also testing on the secondary overlap at a distance of $0 \mathrm{~cm}$ and $10 \mathrm{~cm}$. The design drawing test overlap value is shown in Figure 3.

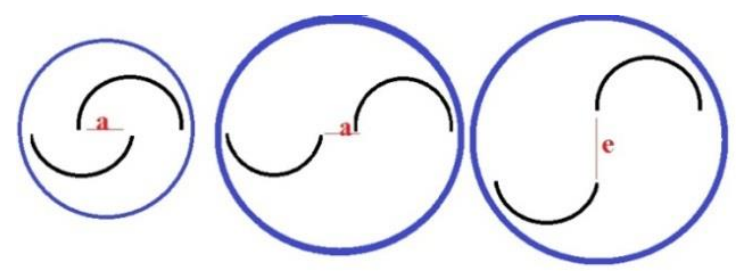

Fig. 3. overlap rasio design

\section{Results and Discussions}

The results obtained by conducting trials on the variation of turbine blade by setting the value of secondary overlap $0 \mathrm{~cm}$ and changing the value of primary overlap at $0 \mathrm{~cm}$ and 10 $\mathrm{cm}$ in positions plus and minus got different rpm value as shown in figure below. 


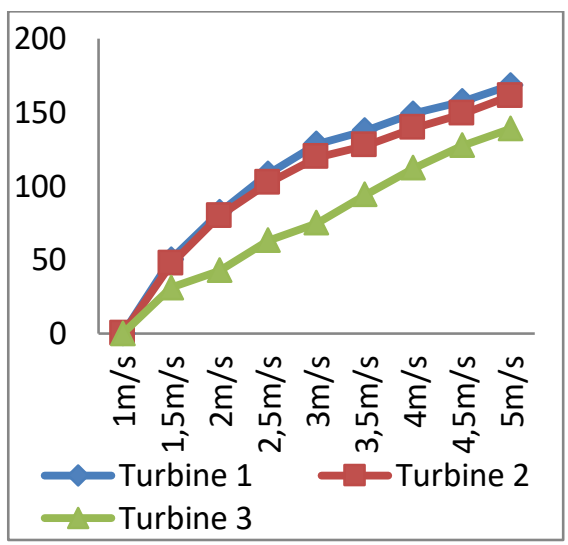

Fig. 4. Primary Overlap $0 \mathrm{~cm}$

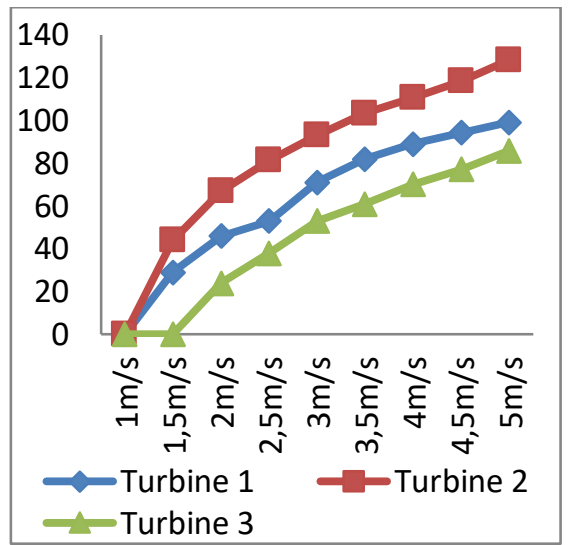

Fig. 5. Primary Overlap plus $10 \mathrm{~cm}$

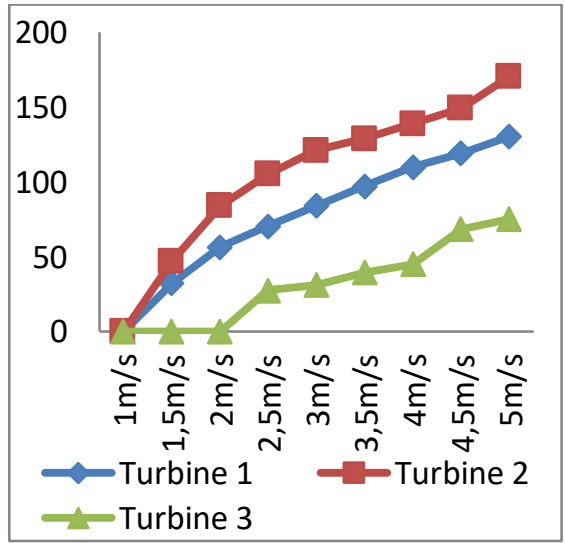

Fig. 6. Primary Overlap Minus $10 \mathrm{~cm}$

The test proved that the dimensions affected the turbine rotation performance, It could be seen that the difference between the height and diameter of the turbine had an important role in the design of the desired turbine design. Based on the graph above it was found that turbine started to rotate was influenced by the dimension ratio between height and diameter, 
for example in figure 6 there was a change to the primary overlap value at minus $10 \mathrm{~cm}$ which means inter interlocking blades. In the turbine experiment 3 , the turbine could rotate at wind speed of $2.5 \mathrm{~m} / \mathrm{s}$ in contrast to turbine 2, where the ratio between the diameter greater than the height that had a positive impact on the performance of turbine rotation obtained also increased as compared to the primary overlap $0 \mathrm{~cm}$ and $10 \mathrm{~cm}$ primary overlap.

The potential of electrical energy that could be generated by using a permanent magnet generator was measured by using a multimeter without the load. Based on the result obtained, the best designed turbine was turbine 2 with dimension ratio $\mathrm{D}>\mathrm{H}$ shown in the following graph.

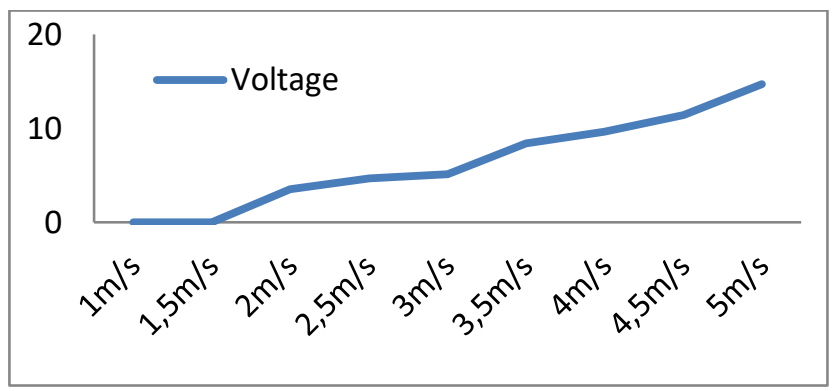

Fig. 7. Potential Energy Electricity wind turbine

The graph showed that turbine rotation to generate electrical energy was obtained when turbine rotated at a speed of $84.2 \mathrm{rpm}$ caused by a wind speed of $2 \mathrm{~m} / \mathrm{s}$ with a potential voltage of electrical energy generated was 3.5 volts. At a wind speed of $5 \mathrm{~m} / \mathrm{s}$, turbine rotated at a speed of $170.5 \mathrm{rpm}$ that was capable of produced 14.7 volt electrical energy voltage, the voltage obtained was qualified to charge the accumulator as a storage medium of electrical energy. Based on that results, it certainly did not necessarily have to wait for a wind speed of $5 \mathrm{~m} / \mathrm{s}$ to charge accumulator. The potential voltage of electric energy can be increased by engineering the increase of turbine rotation ratio to the rotation ratio of the generator so that the electric motion force increases. Engineering can be done by using a gear or belt so that the rotation of the generator can be greater than the efficient turbine rotation in utilizing low-speed wind energy below the wind speed of $5 \mathrm{~m} / \mathrm{s}$.

\section{Conclusions}

The conclusion obtained from the experiment that the best turbine performance is design with a diameter ratio greater than the height, dimensions $H=40 \mathrm{~cm}$ and $\mathrm{D}=60 \mathrm{~cm}$ with the primary overlap value minus $10 \mathrm{~cm}$ and secondary overlap $=0 \mathrm{~cm}$. It is based on the turbine starting to spin and the top speed is better than any other dimension of the designed turbine or among other modifications of the overlapping major value that has been made.

\section{References}

1. Blackwell, B.F, Sheldahl R.E, Feltz, L.V, Wind Tunnel Perfomance Data for two and three bucket Savonious Rorors, (Sandia Laboratories, 1978)

2. C. Sovanara, F. Firdaus, R. Rusdianasari. A review on Enviromental Impact of Wind Energy. Proceeding Forum in Research, Science, Technology (FIRST) (2016) 
3. Fujisawa N. J. Wind Eng Ind Aerod 40 (1992)

4. G.Colley, R.Mishra, H.V.Rao, R.Woolhead, Effect of rotor blade position on vawt peformance (International Conference on Renwable Energies and Power Quality, Granada, 2010)

5. Joseph P. Tillman, Improvements to VAWT blades to aid in self starting, (School of Technology, Eastern Illnois University, 2011)

6. J.V. Akwa, H.A. Vielmo. Renewable and Suistanable Energy Riviews 16 (2012)

7. Kamoji MA, Kedare S.B.J. Experimental Investigations on The Efects of Overlap Ratio and Blade Edge Conditions on the Performance of Conventional Savonious Rotor,(2008)

8. Mohammad Hadi Ali. IJMER 3 (2013)

9. Mohammad Hadi Ali, Experimental Comparison Study for Savonious Wind Turbine of Two and three Blades at Low Wind Speeds, IJMER vol 3 Issue 5 pp 2978-2976, (2013)

10. Mojola O.O. J. Wind Eng Ind Aerod 21 (1985)

11. N.H. Mahmoud, A.A. El Haroun, E.Wahba. Alexandria Engineering Journal 51 (2012)

12. R. Ploetz,R. Rusdianasari, E. Eviliana. Renewable Energy: Advantages and Disadventages. Proceeding Forum in Research, Science, Technology (FIRST) (2016)

13. Savonius S.J, The S rotor and its applications, (Mechanical Engineering, 1931)

14. S.Brusca, R.Lanzafame, M.Messina. International Journal Energy Environmentt Engineering (2014)

15. U.K. Saha, S.Thotla, D.Maity. Journal of Wind Engineering and Industrial Aerodynamics 96 (2008) 